\title{
Pelatihan Pembuatan Paket Wisata Untuk Mendukung Wisata Kuliner Pada Biro Perjalanan Wisata Provinsi Kepulauan Bangka Belitung
}

\author{
Levyda Levyda ${ }^{1}$, Kania Ratnasari ${ }^{2}$, dan Ina G. Djamhur ${ }^{3}$ \\ 1,2,3 Universitas Sahid, Jakarta, Indonesia
}

\begin{abstract}
ABSTRAK
Provinsi Kepulauan Bangka Belitung memiliki potensi wisata kuliner yang besar. Biro perjalanan wisata memiliki peran dalam mengoptimalkan wisata kuliner melalui paket wisata yang dibuat dan ditawarkan pada wisatawan. Pelatihan ini bertujuan untuk meningkatkan pengetahuan dan pengalaman Biro Perjalanan Wisata tentang paket wisata. Metode pelatihan yang digunakan adalah presentasi, simulasi pembuatan paket wisata 4 hari 3 malam dan kunjungan lapangan. Hasil dari pre dan post test menunjukan bahwa pengetahuan peserta mengalami peningkatan. Hasil analisis konten pada paket wisata yang dibuat peserta, menunjukan peserta mampu membuat atraksi wisata kuliner yang eksplisit. Beberapa UMKM kuliner layak sebagai atraksi wisata kuliner.
\end{abstract}

Kata kunci: paket wisata, wisata kuliner, kuliner otentik, biro perjalanan wisata, simulasi

\begin{abstract}
Bangka Belitung Islands Province has great culinary tourism potential. Tour operators have a role in optimizing culinary tourism through creating tour packages offered to tourists. The objective of this training is to enhance the knowledge and experience of tour operators regarding package tours. The training methods are conducted through presentations and simulations of designing a 4days/3nights cullinary tour package as well as field trips. Pre and post-tests results showed that participants' knowledge is improved. The results of content analysis on tour packages made by participants, showed that the participants were capable in creating an explicit culinary attractions. Some culinary medium enterprises considered suitable as a cullinary attractions.
\end{abstract}

Keywords: tour packages, culinary tourism, authentic culinary, tour operators, simulation

\section{PENDAHULUAN}

Provinisi Kepulauan Bangka Belitung memiliki potensi wisata kuliner yang besar karena didukung oleh supply chain wisata kuliner yang terdiri dari penyedia bahan baku kuliner yaitu sektor pertanian, perkebunan dan perikanan, perusahan pengolah kuliner yang terdiri dari toko oleh-oleh, restoran, dan agrowisata yang menwarkan pengalaman wisata kuliner (Levyda et al., 2019a). Wisata kuliner juga sangat penting bagi Bangka Belitung karena mendukung keberadaan UMKM pangan dan kearifan lokal (Levyda et al., 2021). Belanja wisatawan untuk makan dan minum juga besar yaitu 30\% (BPS - Statistics Indonesia, 2017). 
Wisata kuliner di Bangka Belitung juga cukup beragam yaitu menikmati kuliner di restoran lokal, belanja oleh-oleh dan agrowisata (Levyda et al., 2020b, 2020a; Ratnasari et al., 2019) dan memiliki kuliner otentik yang menunjang wisata kuliner (Levyda et al., 2019). Wisata kuliner berpotensi sebagai wisata sekunder bagi Bangka Belitung (RENCANA INDUK PEMBANGUNAN KEPARIWISATAAN PROVINSI KEPULAUAN BANGKA BELITUNG TAHUN 20162025, 2016)

Bagi wisatawan, wisata kuliner tidak tergantikan oleh pengalaman digital karena tujuan wisata kuliner adalah untuk mendapat pengalaman yang menyenangkan. Oleh karena itu wisatawan cenderung loyal (Kementerian Pariwisata dan Ekonomi Kreatif, 2021). Saat ini ada kecenderungan wisatawan memposting foto kuliner di media sosial mereka sebelum mengkonsumsi. Hal ini mendorong wisata kuliner semakin popular (Wachyuni \& Yusuf, 2021) Paket wisata yang ditawarkan Biro Perjalanan Wisata, belum mengoptimalkan atraksi wisata kuliner di Bangka Belitung dan belum memaparkan pengalaman wisata kuliner secara eksplisit sebagai atraksi yang ditawarkan pada wisatawan (Levyda et al., 2020a). Oleh karena itu diperlukan peningkatan pengetahuan dan kemampuan pembuatan paket wisata yang mendukung wisata kuliner. Tujuan pengabdian kepada masyarakat adalah untuk meningkatkan kemampuan BPW dalam merancang paket wisata yang mendukung wisata kuliner di Bangka Belitung.

\section{Paket Perjalanan Wisata}

Paket wisata merupakan sebuah produk perjalanan yang diproduksi dan dipasarkan oleh suatu biro perjalanan wisata atau dipasarkan oleh biro perjalanan wisata lain (Project \& Growth, 2015). Paket perjalanan wisata merupakan kombinasi atau gabungan dari komponen-komponen pariwisata yang terdiri atas transportasi, akomodasi, atraksi wisata, makanan dan minuman, serta jasa tour leader yang dijual ke wisatawan dalam satu harga (Holloway \& Humpreys, 2019). Paket wisata dapat dikelompokkan berdasarkan jumlah peserta tour, alat transportasi, jenis makanan, jarak ke destinasi, jangka waktu wisata, dan tujuan (Project \& Growth, 2015).

Paket perjalanan wisata dibuat melalui tahap-tahap pengembangan paket wisata digambarkan sebagai berikut. 


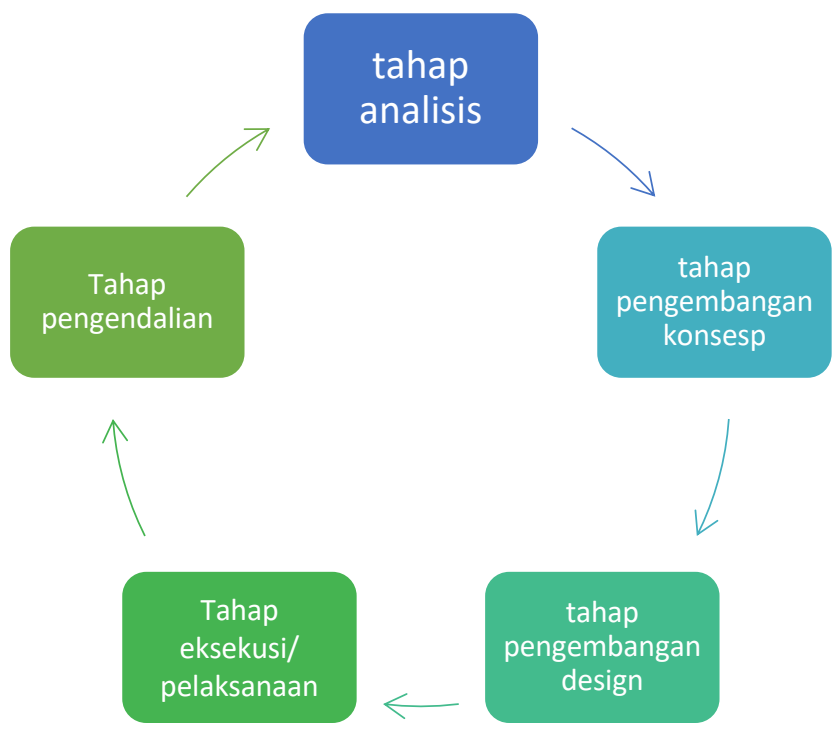

Pada tahap analisis dikaji perilaku konsumen, supplier, dan faktor-faktor yang akan mempengaruhi permintaan paket wisata seperti faktor ekonomi, iklim dan cuaca, sumber daya alam, budaya, infrastruktur, fasilitas dan harga akomodasi dan atraksi pariwisata. Hasil analisis digunakan untuk mengembangkan konsep paket wisata yang sesuai trend, misalnya wisata wisata budaya, wisata kuliner dan selanjutnya menetapkan tema paket wisata.

Archer (2003) menjelaskan tahap-tahap pembuat paket wisata dimulai dari riset pasar. Riset pasar bertujuan untuk mengenali karakteristik, kebutuhan, keinginan, pola perjalanan pasar sasaran. Berdasarkan informasi pasar langkah selanjutnya adalah menentukan destinasi ataupun tempat-tempat wisata yang akan dikunjungi. Setelah ditentukan tempat-tempat yang berpotensi untuk dikunjungi, tahap selanjutnya adalah membuat kontrak dengan industri pariwisata seperti akomodasi, transportasi, restoran, obyek wisata dan sebagainya, Setelah kontrak disepakati, dilanjutkan dengan menghitung dan menetapkan biaya serta harga jual paket wisata. Untuk memasaran paket wisata, maka perlu dibuat brosur atau atau alat promosi lain. Tahap terakhir adalah pembuatan itinerary serta penerbitan dokumendokumen perjalanan seperti voucher, tiket, dan lainnya. Seluruh komponen berkolaborasi dan bekerjasama menciptakan suatu produk yang saling terkait dan tak terpisahkan untuk tujuan memenuhi kebutuhan dan kepuasan wisatawan selama melakukan perjalanan. 
Gambar 1. Proses Pembuatan Paket Wisata

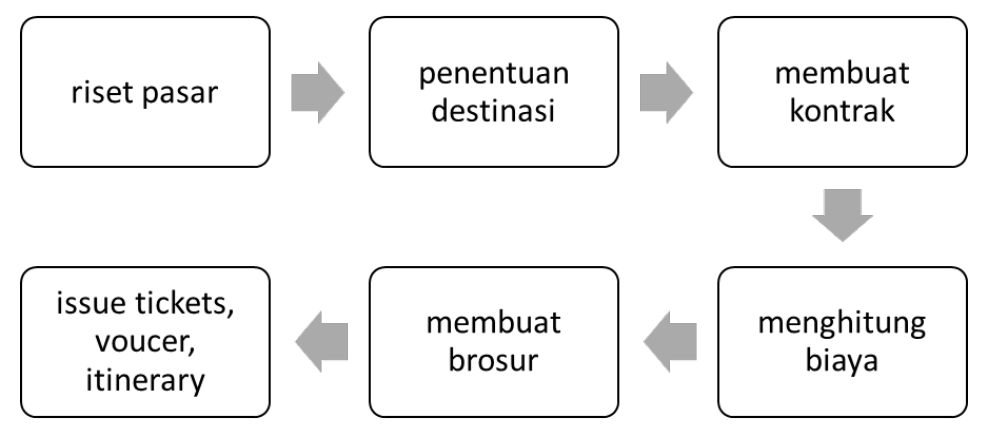

\section{Wisata Kuliner dan Kuliner Otentik}

Wisata kuliner merupakan atraksi yang menarik wisatawan (Baltescu, 2016) sehingga perlu ditamplikan secara eksplisit dalam paket wisata. Menurut Smith \& Xiao (2008), atraksi wisata kuliner dapat digolongkan dalam:

1. fasilitas wisata kuliner yang dikunjungi wisatawan

2. aktivitas yang dilakukan wisatawan

3. events terkait kuliner yang akan dikunjungi

Kuliner otentik dapat diartikan sebagai kuliner dengan resep tradisional, menggunakan bahan baku lokal, diproduksi dan dipasarkan ditempat yang tidak jauh dari tempat produksinya. Makanan otentik merupakan juga merupakan atraksi yang perlu dipertimbangkan dalam paket wisata (de Vries \& Go, 2017; Sidali \& Hemmerling, 2014). Bangka Belitung memiliki makanan otentik yang dapat menjadi atraksi wisata (Levyda et al., 2019). Agar wisata kuliner dikalangan wisatawan, maka kuliner lokal sebaiknya dinyatakan secara eksplisit pada paket wisata.

\section{METODE PELAKSANAAN}

Pelatihan dilaksanakan tanggal 13-14 Desember 2021 di Pangkal Pinang Bangka. Proses pengabdian kepada masyarakat terbagai dalam persiapan, pelaksanaan dan evaluasi. Pada tahap persiapan, aktivitas yang dilakukan adalah koordinasi dengan Dinas Pariwisata Kota Pangkal Pinang dan koordinasi GIPI (Gabungan Industri Pariwisata Indonesia), HPI (Himpunan Pramuwisata Indonesia), ASITA (Asosiasi Perjalanan Wisata), ASATI (Asosiasi Sales Representative dan Travel Indonesia) dan PHRI (Persatuan Hotel dan Restoran Indonesia) DPD Bangka Belitung. Pada tahap pelaksanaan terdiri dari dua aktivitas yaitu pelatihan yang dilaksanakan ruang serbaguna Bangka Botanical Garden dan kunjungan lapangan. Pelatihan di Botanical Garden dilaksanakan tanggal 13 Desember 2021 terdiri dari dua aktivitas utama yaitu presentasi dan simulasi. Kunjungan lapangan dilaksanakan pada tanggal 14 Desember 2021. Obyek wisata yang dikunjungi adalah restoran lokal dan UMKM kuliner yang diusulkan peseta dalam paket wisata.

Metode PKM yang digunakan pada kegiatan ini adalah presentasi dan simulasi. Metode presentasi merupakan penyajian materi dalam langkah-langkah kecil agar dapat dipahami peserta didik (Afandi 
et al., 2013). Materi yang dipresentasikan adalah hasil penelitian tentang kuliner otentik Bangka Belitung dan jenis-jenis wisata kuliner, peran wisata kuliner Rencana Induk Pembangunan Kepariwisataan Provinsi Bangka Belitung Tahun 2016-2025, karakteristik wisata kuliner, tren pariwisata 2022 yang fokus pada penambah pengetahuan dan pengalaman wisatawan dan proses penyusunan paket wisata Keberhasilan pemaparan diukur dengan membandingkan nilai pre test dan nilai post test. Dari selisih nilai tersebut, selanjutnya dilakukan pengkajian.

Metode simulasi digunakan untuk meningkatkan kreativitas, kerjasama dan komunikasi peserta, Simulasi merupakan pembelajaran yang mengandung ciri-ciri kehidupan yang nyata (Afandi et al., 2013). Tujuan simulasi paket wisata agar peserta medapat pengalaman penciptaan paket wisata, kerja sama dan komunikasi. Langkah-langkah simulasi adalah:

1. penetapan topic dan tujuan yang akan dicapai

2. peserta dibagi dalam dua kelompok

3. penugasan kelompok untuk menyusun paket wisata 4 hari 3 malam

4. presentasi kelompok

5. umpan balik

Dalam membuat simulasi peserta diminta untuk mempertimbangkan atraksi wisata kuliner yang ditawarkan kepada wisatawan. Evaluasi kegiatan, dilakukan dengan analisis konten paket wisata. Peserta dinilai mampu membuat paket wisata, bila dalam paket wisata terdapat kegiatan atraksi wisata kuliner dan kuliner otentik.

\section{HASIL DAN PEMBAHASAN}

Peserta pelatihan ini yaitu pemilik biro perjalanan wisata yang terdiri dari 16 orang pemilik Biro Perjalanan Wisata. 12\% berasal dari Sungai Liat Kabupaten Bangka, 12\% dari Muntok Kabupaten Bangka Barat dan 25\% berasal dari Kota Pangkal Pinang. Sebagian besar peserta adalah laki-laki dan $12,5 \%$ peserta adalah perempuan. $12,5 \%$ peserta berpendidikan D4/Sarjana, 12,5\% berpendidikan D1/D2/D3, dan 75\% berpendidikan SMA. Pengalaman peserta dalam bisnis biro perjalanan wisata cukup beragam. Sebagian besar peserta $(62,5 \%)$ baru menyatakan menjalankan usaha kurang dari 5 tahun. 12,5\% peserta sudah menjalankan usaha biro perjalanan wisata antara 5 sampai 10 tahun. 32,5\% peserta sudah berusaha dibidang ini, lebih dari 10 tahun.

Sebelum menyusun paket wisata Biro Perjalanan Wisata harus selalu meningkatkan pengetahuan mereka tentang karakteristik pasar, supplier, pesaing, dan faktor-faktor lingkungan makro seperti peraturan pemerintah, infrastrukur dan fasilitas serta usaha wisata yang terkait dalam paket wisata serta proses pembuatan paket wisata. Setelah fasilitator mempresentasikan hal tersebut, selanjutnya pengetahuan peserta perlu diukur. Untuk mengukur peningkatan pengetahuan peserta maka dilakukan pre-test dan post-test. Hasil dari pre test dan post test penyusunan paket wisata sebagai berikut. 
Tabel 1. Hasil Pre dan Post Test Penyusunan Paket Wisata

\begin{tabular}{|l|c|c|}
\hline Materi & Pre-Test & Post-Test \\
\hline Kategori usaha wisata & $18,75 \%$ & $25 \%$ \\
\hline Komponen paket wisata & $62,5 \%$ & $75 \%$ \\
\hline Jenis paket wisata & $37,5 \%$ & $43,75 \%$ \\
\hline Jenis perjalanan wisata & $68,75 \%$ & $75 \%$ \\
\hline Proses pembuatan paket wisata & $62,5 \%$ & $87,5 \%$ \\
\hline
\end{tabular}

Sumber: data primer

Secara keseluruhan terdapat peningkatan pengetahuan penyusunan paket wisata. Peningkatan signifikan adalah pada proses pembuatan paket wisata. Hal ini diduga terkait dengan metode yang digunakan, yaitu simulasi penyusunan paket wisata.

Dalam simulasi paket wisata muncul beberapa pertanyaan dari peserta tentang jumlah tempat yang dikunjungi dan waktu kunjungan per hari. Produsen kuliner lokal yang dapat dikunjungi wisatawan, jenis pengalaman wisata kuliner dan wisata lain yang dapat ditawarkan pada wisatawan. Rute perjalanan wisata yang dibuat oleh kelompok 1 adalah Pangkal Pinang - Sungai Liat (Kabupaten Bangka) - Bangka Tengah- Pangkal Pinang. Berdasarkan konten analisis pada paket wisata, dapat diidentifikasi jenis wisata kuliner yang ditawarkan pada wisatawan dan penilaian paket wisata.

Tabel Paket Wisata Kuliner Kelompok 1

\begin{tabular}{|c|c|c|}
\hline Paket wisata & Jenis Wisata Kuliner & Penilaian \\
\hline $\begin{array}{l}\text { Hari } 1 \\
\text { Penjemputan di Bandara Dipati Amir, langsung menuju } \\
\text { ke tempat pembuatan mpek-mpek ubi. Setelah ishoma } \\
\text { dilanjutkan perjalanan menuju Museum Timah dan alun- } \\
\text { alun. Selanjutnya menuju ke hotel. }\end{array}$ & $\begin{array}{l}\text { pembuatan mpek- } \\
\text { mpek ubi }\end{array}$ & $\begin{array}{l}\text { Sesuai kriteria } \\
\text { paket wisata }\end{array}$ \\
\hline $\begin{array}{l}\text { Hari } 2 \\
\text { Setelah breakfast, menuju ke Sungailiat di Bangka Induk } \\
\text { dan Pasir Padi dan perjalanan dilanjutkan ke Bangka } \\
\text { Tengah. Kemudian melihat pembuatan rusip yang } \\
\text { merupakan makanan khas Bangka terbuat dari ikan yang } \\
\text { difermentasikan. Kemudian dilanjutkan dengan cooking } \\
\text { class Lampah Kuning. Terakhir berhenti di Restoran } \\
\text { Bukit Angsa Mas. }\end{array}$ & $\begin{array}{l}\text { melihat pembuatan } \\
\text { rusip yang merupakan } \\
\text { makanan khas } \\
\text { cooking class Lampah } \\
\text { Kuning } \\
\text { Restoran Bukit Angsa } \\
\text { Mas }\end{array}$ & $\begin{array}{l}\text { Sesuai kriteria } \\
\text { paket wisata }\end{array}$ \\
\hline $\begin{array}{l}\text { Hari ke } 3 \\
\text { Berangkat menuju Danau Pading di Bangka Tengah dan } \\
\text { dilanjutkan dengan membuat serta menikmati mie Koba }\end{array}$ & $\begin{array}{l}\text { menikmati mie Koba } \\
\text { yang sangat terkenal } \\
\text { dengan rasanya }\end{array}$ & \\
\hline
\end{tabular}




\begin{tabular}{|c|c|c|}
\hline $\begin{array}{l}\text { yang sangat terkenal dengan rasanya. Setelah } \\
\text { merasakan pengalaman pembuatan mie Koba dan } \\
\text { sekaligus menikmatinya, perjalanan dilanjutkan ke } \\
\text { Danau Kaolin yang sangat terkenal. Dari Danau Kaolin, } \\
\text { dilanjutkan dengan jamuan/ritual makan siang ala } \\
\text { Bangka yaitu Bedulang. Selanjutnya mengunjungi Hutan } \\
\text { Pelawan. }\end{array}$ & $\begin{array}{l}\text { jamuan/ritual makan } \\
\text { siang ala Bangka yaitu } \\
\text { Bedulang } \\
\text { mengunjungi Hutan } \\
\text { Pelawan }\end{array}$ & \\
\hline $\begin{array}{l}\text { Hari } 4 \\
\text { Sambil menuju ke bandara, tour dilanjutkan ke tempat } \\
\text { pembuatan kue Yet-Yet dan Ampiang. Kue Yet-Yet } \\
\text { merupakan kue yang melegenda di Bangka yang terbuat } \\
\text { dari tepung beras. Ampiang adalah snacks andalan } \\
\text { pulau Bangka. Menuju bandara. }\end{array}$ & $\begin{array}{l}\text { ke tempat pembuatan } \\
\text { kue Yet-Yet dan } \\
\text { Ampiang. Kue Yet-Yet } \\
\text { merupakan kue yang } \\
\text { melegenda di Bangka }\end{array}$ & $\begin{array}{l}\text { Sesuai kreteria } \\
\text { paket wisata } \\
\text { kuliner }\end{array}$ \\
\hline
\end{tabular}

Dari paket wisata yang dibuat oleh kelompok 1, aktivitas wisata kuliner yang ditawarkan adalah:

1. mengunjungi pabrik pembuatan kuliner khas Bangka

2. mengikuti cooking class

3. menikmati kuliner khas Bangka di restoran lokal

4. menikmati cara makan masyarakat Bangka yaitu makan Bedulang

5. mengunjungi hutan Pelawan yaitu hutan tempat habitat jamur pelawan dan madu pelawan.

Kuliner Bangka yang dikenalkan dalam paket wisata adalah:

1. mpek-mpek ubi

2. rusip

3. lempah kuning

4. mie koba

5. kue yet-yet

6. ampiang

Rute paket wisata yang ditawarkan kelompok 2 adalah Pangkal Pinang - Karau dan Namang (Bangka Tengah)- Belinyu-Sungai Liat (Kabupaten Bangka) - Pangkal Pinang. Analisis konten pada paket wisata, dapat diidentifikasi beberapa jenis wisata kuliner dan kuliner yang dapat dinikmati wisatawan. Berdasarkan jenis wisata kuliner dan kuliner yang ditawarkan, dapat dibuat penilaian.

Tabel Paket Wisata Kuliner Kelompok 2

\begin{tabular}{|l|l|l|}
\hline Paket Wisata & Jenis Wisata Kuliner & Penilaian \\
\hline Hari ke 1 & melihat dan memetik & Sesuai kriteria paket \\
Setibanya di bandara Depati Amir, & Jamur/Kulat Pelawan, & wisata \\
perjalanan menuju Desa Nelayan Kurau di & melihat pembuatan madu. & \\
Kab. Bangka Tengah sambil mengunjungi & & \\
\hline
\end{tabular}




\begin{tabular}{|c|c|c|}
\hline $\begin{array}{l}\text { rumah warna warni. Dilanjutkan ke hutan } \\
\text { Mangrove Munjang di Kurau Barat, Koba } \\
\text { sambil mengunjungi Hutan Pelawan untuk } \\
\text { melihat dan memetik Jamur/Kulat Pelawan } \\
\text { yang sangat langka dan mahal, serta melihat } \\
\text { pembuatan madu. Setelah itu, makan siang } \\
\text { di Namang dengan jamuan Bedulang. } \\
\text { Menuju ke Pangkalpinang, mampir di } \\
\text { Bangkat Botanical Garden dan Pantai Pasir } \\
\text { Padi. Makan malam menikmati Ketam } \\
\text { (Kepiting Hitam) }\end{array}$ & $\begin{array}{l}\text { makan dengan jamuan } \\
\text { Bedulang. } \\
\text { Makan malam menikmati } \\
\text { Ketam (Kepiting Hitam) }\end{array}$ & \\
\hline $\begin{array}{l}\text { Hari ke } 2 \\
\text { Setelah makan pagi, perjalanan dilanjutkan } \\
\text { ke tempat pembuatan Kemplang udang dan } \\
\text { Mpek Mpek udang. Mengunjungi Jembatan } \\
\text { Emas, dan makan siang di Seafood Aju yang } \\
\text { terkenal dengan Kepiting Asap. Menuju } \\
\text { Belinyu mengunjungi kota tua, benteng Kuto } \\
\text { Panji, dan langsung ke tempat pembuatan } \\
\text { otak-otak serta mencicipi es kacang merah. } \\
\text { Makan malam di Pantai Penyusuk dengan } \\
\text { sajian seafood. }\end{array}$ & $\begin{array}{l}\text { Mengunjungi tempat } \\
\text { pembuatan kemplang } \\
\text { udang dan Mpek Mpek } \\
\text { udang. } \\
\text { makan siang di restoran } \\
\text { lokal } \\
\text { tempat pembuatan otak- } \\
\text { otak serta mencicipi es } \\
\text { kacang merah } \\
\text { Makan malam direstoran } \\
\text { lokal }\end{array}$ & \\
\hline $\begin{array}{l}\text { Hari ke } 3 \\
\text { Menuju ke Sungailiat dengan mengunjungi } \\
\text { kawasan pantai Tongaci, pantai Tikus Emas } \\
\text { sambil makan siang di Raja Laut. Setelah itu, } \\
\text { cooking class di Kembang Katis dan makan } \\
\text { malam dengan menu Lempah Darat sambil } \\
\text { menyaksikan dinner with show Tarian } \\
\text { Campuk dan Selendang Khas Bangka. }\end{array}$ & cooking class Lempah Darat & $\begin{array}{l}\text { Sesuai kriteria paket } \\
\text { wisata }\end{array}$ \\
\hline $\begin{array}{l}\text { Hari ke } 4 \\
\text { Perjalanan kembali ke bandara di Dipati } \\
\text { Amir dengan berhenti dan membeli oleh- } \\
\text { oleh Pulau Bangka. }\end{array}$ & $\begin{array}{l}\text { membeli oleh-oleh Pulau } \\
\text { Bangka. }\end{array}$ & $\begin{array}{l}\text { Sesuai kriteria paket } \\
\text { wisata }\end{array}$ \\
\hline
\end{tabular}

Sumber: Hasil Simulasi Kelompok

Dari paket wisata yang dibuat oleh kelompok 1, aktivitas wisata kuliner yang ditawarkan adalah:

1. melihat dan memetik jamur pelawan

2. melihat pembuatan madu

3. mengunjungi pabrik kuliner lokal

4. makan di lokal restoran

5. mengikuti cooking class

6. menikmati sajian bedulang 
7. membeli oleh-oleh

Kuliner Bangka yang dikenalkan melalui paket wisata adalah:

1. jamur pelawan

2. madu pelawan

3. kepiting hitam (ketam)

4. mpek-mpek udang

5. kemplang udang

6. es kacang mereh

7. lempah darat

Dari paket wisata yang buat oleh kelompok 1 dan 2 disimpulkan bahwa kedua kelompok telah mampu membuat paket wisata yang secara eksplisit menyebutkan aktivitas wisatawan yaitu :

1. mengujungi pabrik pembuatan makan

2. mengikuti cooking class

3. menikmati makanan khas Bangka di retoran lokal

4. melihat membuatan madu

5. memetik jamur kulat

Paket wisata yang dibuat juga menjelaskan secara eksplisit makanan lokal yang akan dinikmati oleh wisatawan.

Foto 1 : Presentasi narasumber

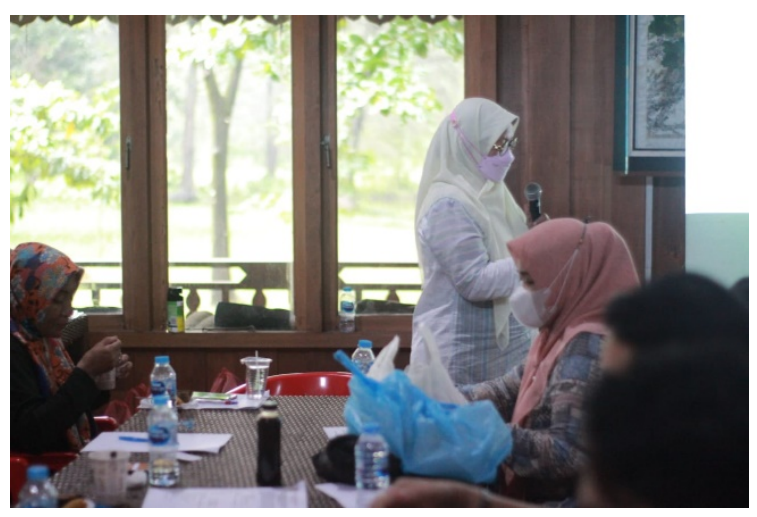

Foto 2. Presentasi Kelompok

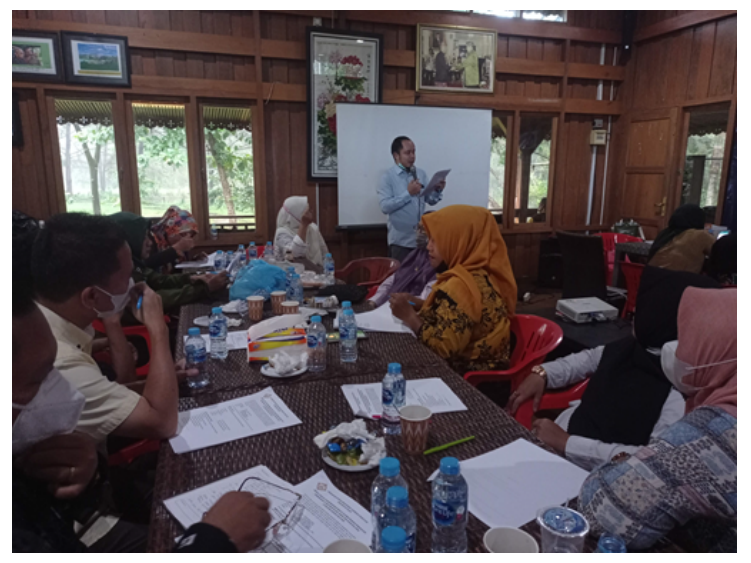


Foto 3. Bersama Mitra PKM

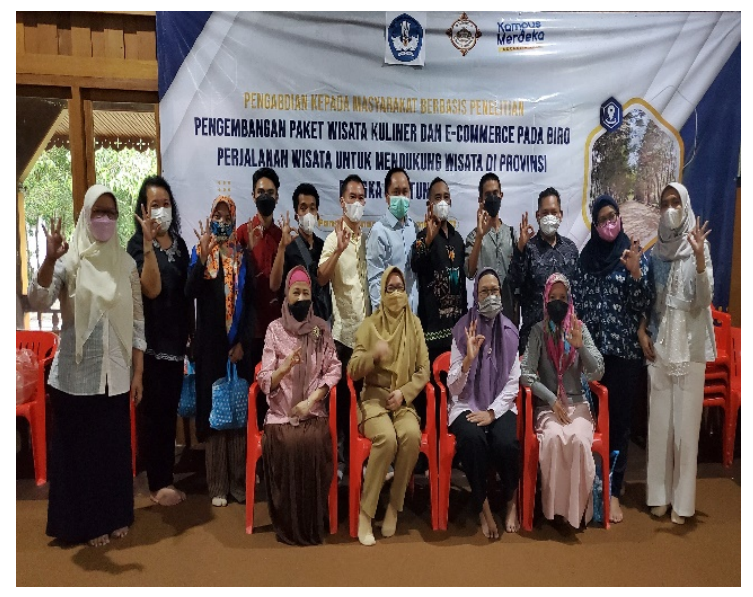

Foto 4. Kunjungan ke UMKM Kuliner

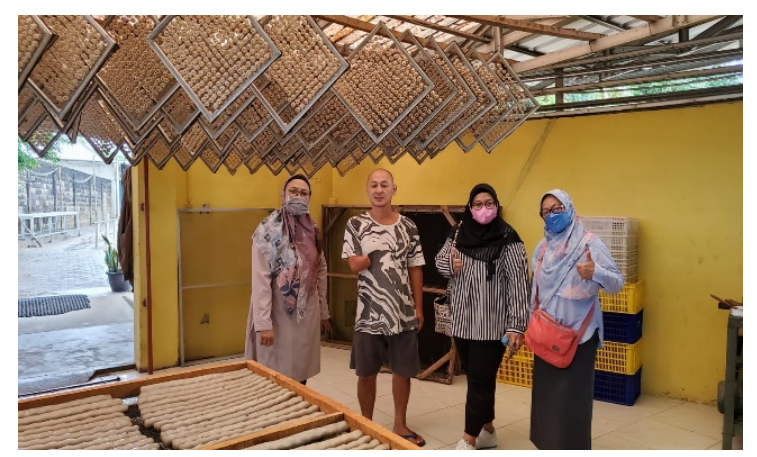

Foto 5. Kunjungan ke Dinas Pariwisata Pangkal Pinang

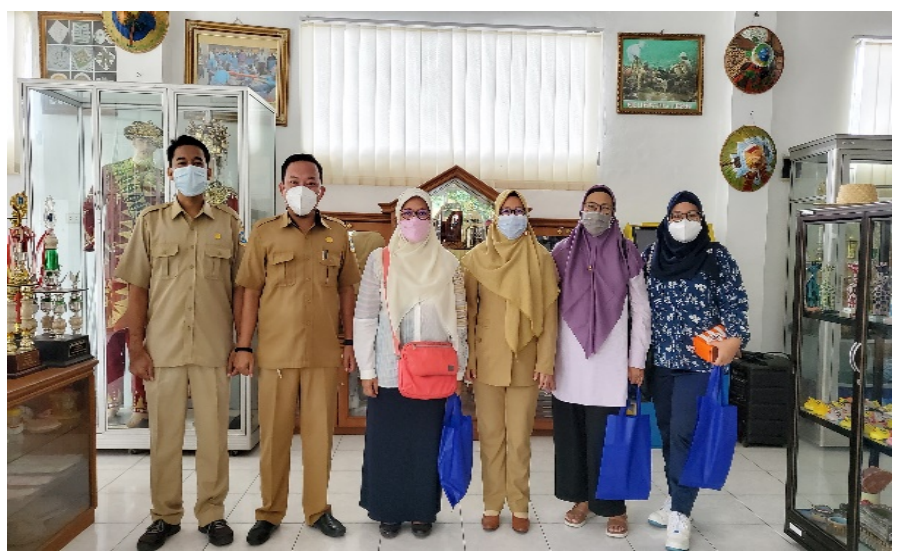

\section{SIMPULAN}

Pelatihan ini bertujuan untuk meningkatkan kemampuan Biro Perjalanan Wisata (BPW) dalam membuat paket wisata kuliner. Hasil dari kegiatan ini adalan adanya peningkatan kemampuan BPW dan keragaman itinerary wisata kuliner yang dapat ditawarkan pada wisata kuliner, yaitu 
penawaran pada wisatawan untuk melihat pembuatan makanan dan menikmati khas Bangka seperti mpek-mpek ubi khas, rusip, kue yet-yet, lempah kuning, mie Koba, jamur Kulat, madu Pelawan, Ketam (Kpiting Hitam), otak-otak, es kacang merah, lempah darat. Kuliner ini perlu masukkan dalam paket wisata agar dikenal wisatawan dan menjadi daya tarik.

\section{UCAPAN TERIMA KASIH}

Terima kasih kepada Kementerian Pendidikan, Kebudayaan, Riset dan Teknologi atas bantuan dana untuk kegiatan ini. Dana berasal dari "Bantuan Pendanaan Program Penelitian Kebijakan Merdeka Belajar Kampus Merdeka Dan Pengabdian Kepada Masyarakat Berbasis Penelitian dan Purwa Rupa Perguruan Tinggi Swasta tahun anggaran 2021".

\section{DAFTAR PUSTAKA}

Archer, J., Syratt., G. 2003. Manual of Travel Agency Practice. Routledge; 3 edition. Baltescu, C. (2016). Culinary experiences as a key tourism attraction. Case Study: Brasov County. Bulletin of the Transilvania University of Brasov, 9(58), 107-112.

BPS - Statistics Indonesia. (2017). Neraca Satelit Pariwisata Nasional (NASPERNAS) 2017 [National Tourism Satellite Account 2017] (Subdirectorate of Tourism Statistic (ed.)). Badan Pusat Statistik.

https://www.bps.go.id/publication/2019/03/26/66604e9f077983c15b80e2bc/neracasatelit-pariwisata-nasional--nesparnas--201

de Vries, H. J., \& Go, F. M. (2017). Developing a common standard for authentic restaurants. Service Industries Journal, 37(15-16), 1008-1028. https://doi.org/10.1080/02642069.2017.1373763

Levyda, L., Giyatmi, G., \& Ratnasari, K. (2020a). IDENTIFIKASI WISATA KULINER DI PULAU BANGKA (IDENTIFICATION OF CULINARY TOURISM IN BANGKA ISLAND). Journal of $\begin{array}{llll}\text { Tourism Destination } & \text { 8nd }\end{array}$ http://journal.univpancasila.ac.id/index.php/jtda/article/view/1408

Levyda, L., Giyatmi, G., \& Ratnasari, K. (2020b). Surat Pencatatan Ciptaan. In KOMPILASI DATA TIPOLOGI WISATA KULINER DI PROVINSI BANGKA BELITUNG.

Levyda, L., Giyatmi, G., \& Ratnasari, K. (2019). What is the authentic food in this destination ? The 2nd Mulawarman International Conference on Economics and Business, 25-30. http://journal.feb.unmul.ac.id/index.php/MICEBProceeding/article/view/7059/900

Levyda, L., Ratnasari, K., \& Giyatmi, G. (2021). Authentic food souvenir to support msmes and local wisdom in bangka belitung, Indonesia. Geojournal of Tourism and Geosites, 
35(2), 531-536. https://doi.org/10.30892/GTG.35234-681

Project, A., \& Growth, B. (2015). Guide for the development of Tourism Packages based on Artificial Reefs.

Ratnasari, K., Levyda, L., \& Giyatmi, G. (2019). WISATA KULINER SEBAGAI PENUNJANG PARIWISATA DI PULAU BELITUNG. Pariwisata Pesona, 04(1), 1-10.

Sidali, K. L., \& Hemmerling, S. (2014). Developing an authenticity model of traditional food specialties : Does the self-concept of consumers matter? British Food Journal, 116(11), 1692-1709. https://doi.org/http://dx.doi.org/10.1108/ BFJ-02-2014-0089 